\title{
What's in a congress?
}

\section{Phil Wiffen}

Its congress time again and I started to think about how this year's congress will affect my thinking. How do we use these few days of intense activity marked by long days and late nights?

Some of us will try and get to everything possible, some will seek to widen our knowledge and look for new ideas we can take on board, for others it is an opportunity to renew acquaintances and enjoy the social aspects while others love to work the exhibition and collect bags of 'stuff'. In practice it is probably a range of these.

For me the conference used to be a place where I kept in touch with developments in my specialty-more often than not attending medical rather that pharmacy meetings. Now I find I am attending less but trying to catch up online.

The medical conference is dead-long live the medical conference. So says Len Starnes-a digital healthcare consultant.

Starnes argues that the format of the medical conference has largely remained unchanged for 100 years or so but the concept of a meeting is changing as we are much more in touch with colleagues that we used to be. He goes on to argue that there are now two types of attendees in the newer medical conferences. The

Correspondence to Professor Phil Wiffen, Pain Research Unit, Old Rd, Churchill Hospital, Oxford OX3 7LE, UK; phil.wiffen@ndcn.ox.ac.uk first is still the physical attendee. This person accepts that the programme will be set by the organisation using a variety of means but usually a panel of considered experts. In practice the programme will only partly meet the needs of the majority of attendees but that is widely understood and accepted. The physical attendee sees value in being there and enjoys engaging with presenters and attendees.

A second emerging type is the virtual attendee. This person can influence the programme and sees conferences as a continuous event, rarely attending in person, they follow live or via recordings. They don't need to arrange travel and can attend when it suits them without disrupting their diaries. There are economic advantages and conferences are never full in the virtual world. In addition they can 'attend' a conference anywhere in the world without the hassle of long haul travel and the virtual conference benefits from a wider international organisation. Digital media enables the virtual attendee to interact as much as the physical attendee.

There is evidence that medical conferences are increasingly embracing the virtual concept by providing live and streamed recoded material so 'attendees' are not limited to a certain space in a diary.

This will of course have an impact on Pharma and those exhibition pitches offering promotions, refreshments and persuasion. Booths will need to become more science focused and interactive and the concept of the 'Sage on the Stage' seen at so many conferences will almost certainly disappear.

So here are some tips for surviving the congress. First, take time to go through the programme and highlight those things which you want to get to. Regard the programme rather like a food buffet. Dip in and out to meet your needs. Talk to friends and colleagues about what they are doing as they may have spotted something good that you missed. Go with the flow and follow what interests you but feel free to change your plans. Aim to have some good conversations on topics that are relevant to you. Finally aim to talk with people you have not met before, there is a huge amount of talent available to tap into.

So what is in the 2015 EAHP congress for you? Hopefully you will leave having been educated and inspired to develop hospital pharmacy within your sphere of influence and that your luggage won't be overweight with all those freebies.

Competing interests None.

Provenance and peer review Commissioned; internally peer reviewed.

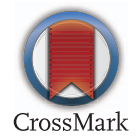

To cite Wiffen P. Eur J Hosp Pharm 2015;22:63.

Published Online First 16 January 2015

Eur J Hosp Pharm 2015;22:63.

doi:10.1136/ejhpharm-2015-000641 